\title{
Author Index to Volume 11 (1992)
}

Angell, I.O., see Kendall, J.E., (3) 123-135

Antonelli, C., Information Economics and Industrial Organization, (2) 53-60

Bush, D.H. and Dooley, K.J., A Learning Process for Transformation to Continuous Improvement Management, (4) 181-192

Dooley, K.J., see Bush, D.H., (4) 181-192

Earl, P.E., The Evolution of Cooperative Strategies: Three $\mathrm{Au}-$ tomotive Industry Case Studies, (2) 89-100

Eom, S.B. and Min, H., The Changing Role of Multiple Criteria in Decision Support Systems, (3) 137-144

Everett, M.J., see Langlois, R.N., (2) 67-75

Filios, V.P., Where Should be the Trends in Current Accounting Research? (Some thoughts on methods and tasks), (4) 203-211

Globerson, S., see Shenkar, O., (1) 35-40

Hattem, E., see Shenkar, O., (1) 35-40

Kakati, M., Prescriptive Model for Managing and Organising FMS and CIM Environments, (4) 191-200

Kendall, K.E., see Kendall, J.E., (3) 123-135

Kendall, J.E., Kendall, K.E., Smithson, S. and Angell, I.O., SEER: A Divergent Methodology Applied to Forecasting the Future Roles of the Systems Analyst, (3) 123-135

Khalil, E.L., Hayek's Spontaneous Order and Varela's Autopoiesis: A Comment, (2) 101-105

Lamberton, D.M., Information, Exploratory Behaviour and the
Design of Organizations, (2) 61-65

Langlois, R.N. and Everett, M.J., Complexity, Genuine Uncertainty, and the Economics of Organization, (2) 67-75

Macdonald, S. and Williams, C., The Informal Information Network in an Age of Advanced Telecommunications, (2) 77-87

Machado des Johansson, N., A Sociological Process Model of Organ Transplantation, (1) 23-33

Maruyama, M., Entropy and Beauty, (3) 165-168

Maruyama, M., Anti-Monopoly Law to Prevent Dominance by one Theory in Academic Departments, (4) 219-220

Maruyama, M., Lessons from Japanese Management Failures in Foreign Countries, (1) 41-48

Min, H., see Eom, S.B., (3) 137-144

Schultz, M.C., Leadership and the Power Circle, (4) 213-217

Shenkar, O., Hattem, E., and Globerson, S., Cost-Benefit Analysis of Quality Circles: A Case Study, (1) 35-40

Singer, A.E., Strategy as Rationality, (1) 7-21

Smithson, S., see Kendall, J.E., (3) 123-135

Warner, M., Management Education and Training Strategies in The People's Republic of China: An Overview, (3) 145-156

Williams, C., see Macdonald, S., (2) 77-87

Zikiye, A.A. and Zikiye, R.A., The Impact of Automation on Job Characteristics: New Horizons, (3) 157-163

Zikiye, R.A., see Zikiye, A.A., (3) 157-163

IOS Press

Human Systems Management 11 (1992) 229 